\title{
Epigenetic alterations in gastric cancer (Review)
}

\author{
DU-GUAN FU
}

\author{
Department of Cardiology, Xiangyang Hospital Affiliated to Hubei University of Medicine, \\ Xiangyang, Hubei 441000, P.R. China
}

Received May 4, 2015; Accepted May 22, 2015

DOI: $10.3892 / \mathrm{mmr} .2015 .3816$

\begin{abstract}
Gastric cancer is one of the most common types of cancer and the second most common cause of cancer-related mortality worldwide. An increasing number of recent studies have confirmed that gastric cancer is a multistage pathological state that arises from environmental factors; dietary factors in particulary are considered to play an important role in the etiology of gastric cancer. Improper dietary habits are one of the primary concerns as they influence key molecular events associated with the onset of gastric carcinogenesis. In the field of genetics, anticancer research has mainly focused on the various genetic markers and genetic molecular mechanisms responsible for the development of this of this disease. Some of this research has proven to be very fruitful, providing insight into the possible mechamisms repsonsible for this disease and into possible treatment modalities. However, the mortality rate associated with gastric cancer remains relatively high. Thus, epigenetics has become a hot topic for research, whereby genetic markers are bypassed and this research is directed towards reversible epigenetic events, such as methylation and histone modifications that play a crucial role in carcinogenesis. The present review focuses on the epigenetic events which play an important role in the development and progression of this deadly disease, gastric cancer.
\end{abstract}

\section{Contents}

1. Introduction

2. Epigenetics

3. DNA methylation and epigenetic gene silencing

4. Histone modifications

5. Mechanisms of epigenetic activity

6. Epigenetic alternations in gastric cancer

7. Clinical implications of epigenetics

Correspondence to: Dr Du-Guan Fu, Department of Cardiology, Xiangyang Hospital Affiliated to Hubei University of Medicine, 15 Jiefang Road, Xiangyang, Hubei 441000, P.R. China

E-mail: epspublication@gmail.com

Key words: epigenetics, gastric carcinoma

\section{Introduction}

Gastric cancer is the second most common type of cancer and a leading cause of cancer-related mortality worldwide (1). An increasing number of recent studies have confirmed that gastric cancer is a multistage pathological state that arises from environmental factors; a poor diet is considered to play an imporant role in the development of this disease. Gastric cancer is classified into the intestinal and diffuse type. Differences exist in the pathways and mechanisms leading to the development of these two types of gastric cancer. Intestinal tumors develop and progress through a number of sequential steps. This begins with atrophic gastritis followed by intestinal metaplasia, dysplasia and then cancer. Diffuse gastric cancer is not characterized by any preceding steps other than chronic gastritis associated with Helicobacter pylori $(H$. pylori) infection $(2,3)$.

The pathogenesis of gastric cancer represents a classic example of gene-environment interactions. Among the environmental factors, a poor (unhealthy, high-fat) diet and infection with $H$. pylori are the most common causes of gastric carcinogenesis. Genetic factors play an important role in gastric carcinogenesis due to aberrant gene expression, leading to a malignant phenotype (2). The oncogenic activation of $\beta$-catenin (17-27\% in the intestinal type) and K-ras (0-18\% in both histological types) has been found in gastric cancer $(4,5)$. In addition, amplifications of the c-erbB2 and c-met genes have each been found in approximately $10 \%$ of both histological types. Among the tumor suppressor genes, p53 mutations have been reported in both the diffuse (0-21\%) and intestinal type (36-43\%) (6). Mutations in APC are frequently observed in gastric adenomas, but only rarely in gastric cancers (1). Somatic mutations of E-cadherin are observed specifically in sporadic diffuse type gastric cancer (33-50\%) (7). Runtrelated transcription factor 3 (RUNX3) has been implicated in gastric cancer, although mutations in this gene are rare (8). Microsatellite instability (MSI) is observed in 5-10\% of diffuse type gastric cancer and in 15-40\% of intestinal type of gastric cancer (1).

In addition to these well characterized genetic changes, epigenetic alterations, including promoter $\mathrm{CpG}$ island hypermethylation are the most common molecular alterations in human neoplasia (9). Promoter hypermethylation of mismatch repair gene hMLH1 is the main mechanism responsible for MSI in gastric cancer. Similarly, while the hypermethylation of p16 is common in gastric cancer with a higher incidence in the intestinal type, mutation of the p16 gene is infrequent (10). 
Thus, the present review focuses on the epigenetic alterations observed in gastric cancer.

\section{Epigenetics}

The term 'epigenetics' was first used by Conrad Waddington in 1939 (11) to describe 'the casual interaction between genes and their products'. Subsequently, Riggs et al (12) defined epigenetics as 'the study of mitotically and/or meiotically heritable changes in gene function that cannot be explained by changes in DNA sequence' (9). In the present era, the meaning of the term 'epigenetics' has broadened to include heritable and transient/reversible changes in gene expression that are not accompanied by a change in the DNA sequence.

The critical role of epigenetic modifications in human diseases is coming to the fore. The study of epigenetics has contribued to the comprehensive understanding of different biological activities, such as DNA methylation, chromatin structure, transcriptional activities and histone modification. Two major epigenetic modifications include DNA methylation and chromatin remodeling $(9,10,13)$. While DNA methylation involves a chemical change in the DNA sequence that most commonly occurs at the cytosine moiety of $\mathrm{CpG}$ dinucleotides, chromatin remodeling occurs through histone modifications (primarily on the $\mathrm{N}$-terminal tails) that ultimately affect the interaction of DNA with chromatin-modifying proteins. Both DNA methylation and histone modifications are associated with the silencing of critical tumor suppressor genes and the activation of oncogenes involved in cancer $(9,10,13)$.

The overall 5 year survival rate for patients with gastric cancer is low (10-20\%) (14). The poor prognosis associated with gastric cancer is due to the detection of the tumor at a late stage. Thus, the disovery of novel molecular markers is imperative for the early detection and prognostic prediction of this disease. The use of novel chemotherapeutic agents targeting these newly identified molecular markers may further improve the prognosis of patients with gastric cancer. Various genetic markers have been used for the early detection of tumors and prognostic prediction, as well as in an aim to elucidate the genetic pathway of gastric carcinogenesis $(1,15)$. Epigenetic markers have gained popularity in recent years, particularly promoter hypermethylation and has various advantages over genetic markers. Firstly, promoter hypermethylation is much more common than genetic alterations in cancer. Secondly, promoter hypermethylation occurs in the same defined region of a gene in all forms of cancer in comparison to a wide range of mutational variations in a specific gene. Thus, the epigenetic detection of promoter hypermethylation may be an efficient and cost-effective method for tumor detection. Thirdly, promoter hypermethylation constitutes a 'positive signal' that can be easily detected against a background of normal cells, whereas certain genetic markers, such as the loss of heterozygosity ( $\mathrm{LOH}$ ), homozygous deletion and MSI represent 'negative signals' and are difficult to detect against a background of normal cells (16).

\section{DNA methylation and epigenetic gene silencing}

DNA methylation is a reversible chemical modification of cytosine in the $\mathrm{CpG}$ islands of promoter sequences, catalyzed by a family of DNA methyltransferases. DNA methylation does not alter the genetic information, but only alters the readability of the DNA and results in the inactivation of a gene by subsequent transcript repression (17). DNA methylation plays a critical role in the control of cellular process, including embryonic development, transcription, X-chromosome inactivation and genomic imprinting (18). CpG dinucleotides are not frequently observed throughout the human genome and are present at $20 \%$ of their expected frequency. Approximately half of the human gene promoter regions have $\mathrm{CpG}$-rich regions of $0.5-2 \mathrm{~kb}$ in length where the $\mathrm{CpG}$ dinucleotide frequency is higher than expected. These $\mathrm{CpG}$-rich sequences are often known as $\mathrm{CpG}$ islands (19). The majority (94\%) of $\mathrm{CpG}$ islands remain unmethylated in a normal cell. However, particular subgroups of $\mathrm{CpG}$ island promoters are methylated, such as in tissue and germ line-specific genes. In general, $\mathrm{CpG}$ island methylation is associated with gene silencing. The methylated $\mathrm{CpG}$ island also recruits histone deacetylases and other factors involved in transcriptional silencing (9).

The changes in the DNA methylation status in cancer cells are complex, involving global hypomethylation and localized hypermethylation. Global hypomethylation of the genome was initially considered to be an exclusive event in cancer development (16). The loss of methylation in cancer is mainly due to the hypomethylation of repetitive DNA sequences (LINE and SINE) and the demethylation of inotropic sequences. During the development of a neoplasm, the degree of hypomethylation of genomic DNA increases as the lesion progresses from a benign one to a metastatic one $(9,20)$. Three mechanisms of DNA hypomethylation have been suggested to be involved in the development of cancers: first, the increase in genomic instability, second by the reactivation of transposable elements, and third by the loss of imprinting. The demethylation of DNA can favour mitotic recombination, leading to deletions, translocations and chromosomal instability (9). The aberrant activation of oncogenes due to promoter demethylation (hypomethylation) has yet not been established (20). The exact association between global hypomethylation and the development of cancer remains to be consolidated (9).

Paradoxically, in parallel to global hypomethylation, the genomes of cancer cells are also characterized by localized regions of de novo hypermethylation, typically in the $\mathrm{CpG}$ island of tumor suppressor genes and microRNA (miRNA) genes. The inactivation of tumor suppressor genes through the hypermethylation of $\mathrm{CpG}$ islands within promoter regions is a major event in carcinogenesis (9). The hypermethylation of CpG islands also has a silencing effect on miRNAs in cancer. miRNAs are short, non-coding RNAs (18-22 nucleotides in length), that regulate a number of cellular functions, including cell proliferation, apoptosis and differentiation by silencing specific target genes through translational repression or mRNA degradation $(21,22)$.

In the recent past, a number of genes that are critical in tumorigenesis that undergo epigenetic silencing have been identified. These include various genes involved in different cellular process, such as cell cycle regulation $\left(\mathrm{p} 16^{\mathrm{NK} 4 \mathrm{a}}, \mathrm{p} 15^{\mathrm{INK} 4 \mathrm{~b}}\right.$ and p14 ${ }^{\mathrm{ARF}}$ ), DNA repair [human mutL homolog 1 (hMLH1) and methylguanine DNA methyltransferase (MGMT)], cell-cell/ cell matrix adhesion (E-cadherin, $\mathrm{H}$-cadherin and adenomatous polyposis coli), apoptosis [death-associated protein kinase 
(DAPK), TMS1 and caspase-8] and angiogenesis [thrombospondin-1 (THBS-1) and p73] (16).

\section{Histone modifications}

Histones are evolutionarily highly conserved proteins characterized by an accessible aminoterminal tail and a histone fold domain that mediates interactions between histones to form the nucleosome scaffold (9). The N-terminal of histone polypeptides are extensively modified by $>60$ different posttranslational modifications, including methylation, acetylation, phosphorylation, ribosylation, ubiquitination, sumoylation, carbonylation and glycosylation $(9,13,23)$.

In normal cells, a precise balance maintains nucleosomal DNA in either an active/acetylated or an inactive/deacetylated form. This adequate balance is controlled by acetylating enzymes [histone acetyltransferases (HATs)] and deacetylating enzymes [histone deacetylases (HDACs)]. The other modification includes methylation of arginine and lysine residues of histones. This methylation is catalyzed by histone methyltranferase (HMT) and the process is involved in the regulation of a wide range of gene activities and chromatin structures. In general, lysine methylation at $\mathrm{H} 3 \mathrm{~K} 9, \mathrm{H} 3 \mathrm{~K} 27$ and $\mathrm{H} 4 \mathrm{~K} 20$ is associated with gene silencing, whereas methylation at $\mathrm{H} 3 \mathrm{~K} 4$, H3K36 and H3K79 is associated with gene activation (13). The genomic changes in the pattern of $\mathrm{CpG}$ methylation may in turn lead to global changes in histone modification patterns in a number of human cancers. Changes in histone modification patterns independent of $\mathrm{CpG}$ methylation have also been directly linked to cancer development. In addition to their role in transcriptional regulation, histone modifications have been implicated in DNA replication, repair and condensation (9).

\section{Mechanisms of epigenetic activity}

Epigenetic regulation by DNA methylation is possible through DNA methyltransferase (DNMT). In humans, various DNMTs have been identified. DNMT3A and DNMT3B have been implicated in establishing the de novo methylation pattern, whereas DNMT1 is considered to be responsible for maintaining the DNA methylation patterns $(16,24)$. DNMT2 has an unknown biological function. Its strong binding to DNA suggests that it may mark a specific sequence in the genome (13).

There are three main mechanisms through which DNA methylation suppresses gene transcription (25). The first of these is methyl-CpG-binding domain (MBD)-mediated gene silencing. Various methyl-CpG-binding proteins (MBPs) have been identified, such as methyl-CpG-binding protein 2 (MeCP2) and MBD1, MBD2, MBD3 and MBD4. These proteins posses a transcriptional repressor domain, thus directly repressing transcription. In addition, MBDs can recruit transcriptional co-repressors, such as HDACs and Sin3A to methylated DNA $(16,25)$. The deacetylation of chromatin histone results in closed or repressed chromatin configuration, which in turn leads to the exclusion of transcription factors and allele-specific gene silencing. The second mechanism of gene silencing is mediated through DNMTs. All three DNMTs (DNMT1, DNMT3A and DNMT3B) have a transcription repressor domain and can thus directly suppress transcription. In addition, these DNMTs can recruit co-transcriptional repressors, such as HDACs to methyl- ated DNA identical to MBDs. The third mechanism is that $\mathrm{CpG}$ island hypermethylation can sterically interrupt the binding of activating transcription factors to gene promoters (16). The details of histone modifications are discussed above.

Polycomb group $(\mathrm{PcG})$ proteins are epigenetic chromatin modifiers involved in carcinogenesis. Two distinct multiprotein PcG complexes have been identified $(26,27)$. Polycomb repressive complex (PRC)2, which is involved in the initiation of gene repression, and PRC1 that functions as a maintenance complex. The enhancer of zeste homolog 2 (EZH2), a member of PRC2, catalyzes the addition of methyl groups to H3K27 (H3K27 trimethylation). EZH2 also interacts with DNMTs and is essential for the DNA methylation of EZH2 target promoters, suggesting that a direct link exists between PcG-mediated gene repression and DNA methylation (23).

\section{Epigenetic alternations in gastric cancer}

The majority of traditional molecular studies on gastric cancer have focused on identifying genetic mutations causing cancer or on tumor suppressor genes (28-30). However, more studies are now focusing on the discovery of novel biomarkers that are epigenetically silenced in early carcinogenesis (31-33). It has also been observed that almost half of the tumor suppressor genes that causes familial cancers through mutations are also inactivated by promoter hypermethylation in sporadic cancers (23). Increasing evidence suggests that epigenetic changes play a key role in cancer development, including gastric cancer. It has become apparent that different tumor types have a different spectrum, profile or clustering of gene hypermethylation referred to as the $\mathrm{CpG}$ island methylator phenotype (CIMP). The CIMP group was defined as having concordant tumor-specific DNA methylation and clearly distinguished due to exhibiting a higher methylation index in comparison to non-CIMP tumors that show only low levels of tumor-specific methylation (16).

Tumors with concurrent hypermethylation in multiple loci have been defined as CIMP-high (CIMP-H). CIMP plays an important role in the progression of gastric cancer. An et al (34) demonstrated that the concurrent hypermethylation of gene promoters is associated with MSI in gastric cancer with the CIMP-H phenotype. They demonstrated that the concordant methylation of multiple gene/loci found in $31 \%$ of tumors was associated with an improved survival, but was not an independent predictor of prognosis for patients with gastric cancer. Thus the prognostic role of CIMP status in gastric cancer is unclear (10).

The genes such as $\mathrm{p} 16^{\mathrm{INK} 4 \mathrm{a}}, \mathrm{CDKN} 2 \mathrm{~B} / \mathrm{p} 15^{1 \mathrm{NK} 2 \mathrm{~b}}$ and $\mathrm{p} 14^{\mathrm{ARF}}$ are hypermethylated in human cell lines and primary tumors. Silencing of p16(INK4a) by promoter hypermethylation has also been reported in gastric cancer (35). The hypermethylation of p16 may predict the malignant potential of dysplasia and the early diagnosis of cancer. CDKN2A promoter methylation has been reported in $30 \%$ of gastric cancer cases $(10,36)$. CDKN2A hypermethylation may contribute to the malignant transformation of gastric precursor lesions (37). The promoter hypermethylation of hMLH1 is a frequent event in gastric cancer and is associated with the loss of hMLH1 expression in the majority of gastric cancers exhibiting MSI (10,38-40). The methylation of hMLH1 is present in $71 \%$ of tumors with a 
MSI-high (MSI-H) phenotype, but only in $8 \%$ of tumors with a MSI-low (MSI-L) phenotype and in 13\% of tumors with a microsatellite stable (MSS) phenotpye (37). The hypermethylation of the DNA repair protein $\mathrm{O}^{6}$-methylguanine DNA methyltransferase (MGMT) has been found in $31 \%$ of gastric cancer cases (41).

The capacity of cancer cells to migrate and invade other organs using vascular channels is characterized by a variety of genes, such as APC, E-Cadherin (CDH1), H-Cadherin (CDH13) and FAT tumor suppressor cadherin (13). CDH1 promoter hypermethylation has been found in $54.8 \%$ of analyzed cases of sporadic gastric cancer (42) and in 28.6 of cases, the downregulation of E-cadherin may be associated with a poor prognosis [Graziano et al (43)]. Of note, $\mathrm{CDH} 1$ promoter hypermethylation is more frequent in the diffuse histological type (18/20 cases) (43). CDH1 methylation has been shown to be significantly higher in gastric tissue with lymph node (LN) metastasis than in tissue without $\mathrm{LN}$ metastasis, and has been associated with serosal invasion (44). It has been reported that H. pylori infection is associated with E-cadherin methylation, leading to the downregulation of E-cadherin. Of note, H. pylori eradication therapy can reverse methylation in patients with chronic gastritis only and may halt the process of gastric carcinogenesis $(10,45-47)$. CDH4 gene methylation has also been observed at a high frequency in gastric cancer cases and may be an early event in tumor progression (48).

The hypermethylation of DAPK has been observed in the intestinal, diffuse and mixed type of gastric cancer and correlates with the presence of LN metastasis, an advanced stage and poor survival (49). The methylation-associated inactivation of Ras association domain family 1 isoform A (RASSF1A), a tumor suppressor gene, is frequently observed in lung and breast cancer (50). The loss or downregulation of RASSF1 A correlates with the stage and grade of gastric tumors. Methylation at $\mathrm{CpG}$ sites is observed in 95\% of cases of RASSF1A non-expressing primary gastric cancer (50).

The X-linked inhibitor of apoptosis (XIAP) is the most potent member of the IAP family and exerts anti-apoptotic effects by interfering with the activities of caspases. Recently, XIAP-associated factor 1 (XAF1) has been found to negatively regulate the caspase-inhibiting activity of XIAP. The epigenetic silencing of the XAF1 gene by aberrant promoter methylation has been reported in gastric cancer (51). On the other hand, the loss of the expression of caspase-1 (interleukin- $1 \beta$ converting enzyme), a member of the cysteine protease family, is observed in $19.3 \%$ of cases of gastric cancer and this loss in its expression is reversed by treatment with 5-aza-2'-deoxycytidine and/or trichostatin in gastric cancer cell lines (52). The mRNA expression of TSPYL5 is frequently downregulated and inversely correlates with DNA methylation in seven out of nine gastric cancer cell lines (53). In primary gastric cancer, methylationspecific PCR of TSPYL5 has revealed hypermethylation at the $\mathrm{CpG}$ island in 23 out of the $36(63.9 \%)$ cases (53). hSRBC is a putative tumor suppressor gene located at $11 \mathrm{p} 15.4$ and its frequent genomic loss has been observed in several malignancies. hSRBC increases the protein stability of p53 and the expression of p53 target genes, such as p21 (WAF1), PUMA and NOXA, while hSRBC-mediated cell cycle arrest and apoptosis are abolished by the blockade of $\mathrm{p} 53$ function. The loss or reduction of hSRBC expression has been observed in $73 \%$ of cancer cell lines and in $41 \%$ of primary gastric tumors (54). While the allelic loss or somatic mutation of this gene is infrequent, its expression is restored in tumor cells by treatment with 5-aza-2'-deoxycytidine (DNA methyltransferase inhibitor) (54). The activation of Wnt signaling has been implicated in tumorigenesis. Secreted frizzled related proteins (SFRP) are identified as possible negative modulators of the Wnt signal transduction pathway. DICKKOPF (DKK) family genes are identified as Wnt antagonists (56). The downregulated expression of SFRP2 has been shown to correlate with promoter hypermethylation in $73.3 \%$ of cases of primary gastric cancer (56). Nojima et al (57) found a high frequency of CpG methylation in SFRP1, SFRP2 and SFRP5 in both gastric cell lines and primary gastric cancer. The hypermethylation and loss of $\beta$-catenin (CTNNB1) expression, an integral component of the Wnt signaling pathway, has been reported in a subgroup of primary gastric cancer, cell lines and in metastases (58). DKK methylation has also reported in gastric cancer cell lines (55).

The homozygous loss of the very low density lipoprotein receptor (VLDLR) gene and epigenetic silencing by DNA methylation have been reported in gastric cancer cell lines by Takada et al (59). The suppressor of cytokine signaling-1 (SOCS-1) inhibits the signaling of the Janus kinase (JAK)/signal transducers and activators of transcription (STAT) pathway by several cytokines and has tumor suppressor activity. Oshimo et al detected the hypermethylation of the SOCS-1 gene in $44 \%$ (33/75) of cases of gastric cancer. The methylation of the SOCS-1 gene was shown to be associated with the reduced expression of the SOCS gene, LN metastases and an advanced tumor stage (60).

AKAP12/gravin is one of the A-kinase anchoring proteins (AKAPs) which functions as a kinase scaffold protein and dynamic regulator of the $\beta 2$ adrenergic receptor complex. The hypermethylation of two forms of the AKAP12 gene (AKAP12A and AKAP12B) has been demonstrated in gastric cancer (61).

The promoter hypermethylation of the retinoblastoma protein-interacting zinc finger gene (RIZ1), which is involved in chromatin-mediated gene expression and is also a target for frame shift mutation in cancers with the MSI phenotype, has been shown in $69 \%$ of cases of gastric cancer and $21 \%$ of cases of non-neoplastic mucosa (62). An essential epigenetic regulator of the mammalian SWI/SNF chromatin remodeling complex contains the Brm molecule as its catalytic submit. The frequent loss of Brm expression has been observed in gastric cancer cell lines and primary gastric tumors, and this loss in its epxression is reversed by treatment with HDAC inhibitors in gastric cancer cell lines, suggesting the epigenetic regulation of this gene (63). It has been demonstrated that members of the SWI/SNF superfamily can function as tumor suppressor genes. The methylation HLTF, a homologue of SWI/SNF, has been reported in $50 \%$ of cases of gastric cancer (64).

Among the RUNX gene family, RUNX3 is often involved in gastric carcinogenesis. The hypermethylation of the CpG island of RUNX3 has been reported in $64 \%$ of cases of gastric cancer (10). Kim et al (65) also found RUNX3 methylation in $8 \%$ of cases of chronic gastritis, in $28 \%$ of cases of intestinal metaplasia and in $27 \%$ of cases of gastric adenoma.

The promoter hypermethylation of retinoic acid receptor $\beta$ $(\operatorname{RAR} \beta)$ is observed in $64 \%$ of cases of gastric cancer (66). 
Thrombospondin-1 (TSP-1) is a potent peptide linked with angiogenesis in a variety of tumors. The promoter hypermethylation of the TSP1 gene is observed in 33\% of cases of gastric cancer (67). The deleted in liver cancer (DLC-1) gene has been founed to be hypermethylated in $30 \%$ of cases of primary gastric cancer (68). The aberrant methylation of COX-2 has also been observed in gastric cancer $(69,70)$.

Poplawski et al (71) observed aberrant methylation in the promoter regions of multiple genes (CASP8, hMLH1, CDH1 and MDR1) involved in gastric cancer. Of note, the hypermethylation of hMLH1 occurred more frequently in females than in males (71). Lee et al (72) reported the promoter methylation of DAPK, E-cadherin, GSTP1, p15 and p16 in 70, 76, 18, 69 and $67 \%$ of gastric cancer cases, respectively. Kang et al (73) investigated the methylation of multiple genes in gastric cancer tissue, gastric adenoma, intestinal metaplasia and chronic gastritis. Five different classes of methylation behaviours were observed: i) genes methylated in gastric cancer only (GSTP1 and RASSF1A), ii) genes showing a significantly higher methylation frequency in gastric cancer than in other lesions (COX-2, hMLH1 and p16), iii) genes with a high and similar methylation frequency in all four lesions (APC and E-cadherin), iv) a gene with a low and similar methylation frequency in four-step lesions (MGMT), and v) genes showing an increasing methylation frequency during the progression of the disease (DAPK, p14, THBS1 and TIMP-3). The authors concluded that tumor-related genes show a gene type-specific methylation profile along multistep carcinogenesis. Oue et al (74) demonstrated $\mathrm{CpG}$ island hypermethylation of the p16(INK4a), CDH1 and RAR $\beta$ promoters in 27, 58 and $53 \%$ of gastric cancer cases, respectively. In their study, the hypermethylation of the p16 (INK4a) promoter was more common in intestinal type than in diffuse type gastric cancer. $\mathrm{CDH} 1$ and $\mathrm{RAR} \beta$ promoter hypermethylation was more frequently observed in the diffuse scattered type of gastric cancer (74).

Hypomethylation also contributes to gastric carcinogenesis. The demethylation of melanoma antigen (MAGE), synucleingamma (SNCG) and cyclin D2 has been observed in gastric cancer (10). MAGE expression is known to be activated by promethylation. The demethylation of both the MAGE-A1 and A 3 promoters is more frequently observed (29 and 66\%, respectively) in the advanced clinical stages of gastric cancer and is also associated with a poor prognosis (75). SNCG demethylation is common in cases with LN metastasis (76). The hypomethylation of the cyclin D2 promoter is observed in $71 \%$ of cases of gastric cancer. The hypomethylation of cyclin D2 is more common in stage III and IV tumors than in stage I and II tumors (77).

The modification of histone by methylation, which occurs at lysine or arginine residues, is generally associated with gene inactivation or silencing (78-82). Histone modifications also regulate genes that participate in the cell cycle. It has also been reported that methylation of histone $\mathrm{H} 3$ plays an important role in carcinogenesis by silencing tumor suppressor genes $(83,84)$. Park et al (78) observed global histone modification patterns using immunohistochemistry and reported that the trimethylation of $\mathrm{H} 3 \mathrm{~K} 9$ positively correlates with tumor stage and lymphovascular invasion in gastric cancer (78). On the other hand, the acetylation of histone, which occurs mostly at lysine residues of $\mathrm{N}$-terminal domains, is known to be associated with transcriptional activation. The acetylation of histone $\mathrm{H} 3$ at K9 has been shown to be associated with a poorly differentiated or diffuse type of histology (78). Histone $\mathrm{H} 4$ acetylation is reduced in gastric cancer compared to normal mucosa. The reduction of histone $\mathrm{H} 4$ acetylation correlates with a more advanced stage, deeper invasion and a greater extent of LN metastasis (85). In gastric cancer cells, p $21^{\mathrm{WAF} 1}$ is associated with extensive histone acetylation. It has also been reported that reduced histone $\mathrm{H} 3$ acetylation is associated with reduced tumor suppressor gene $\mathrm{p} 21^{\mathrm{WAF} 1 / \mathrm{CIP} 1}$ expression in gastric cancer (86). Histone $\mathrm{H} 4$ acetylation at lysine 16 directs the tumor towards a better prognosis, possibly by activating tumor suppressor genes (78). Xia et al (87) investigated the modulation of the cell cycle control protein p21 (WAF1) by H. pylori in gastric cancer cells and primary gastric cells derived from healthy tissue. Their study revealed that the increased expression of p21 (WAF1) induced by H. pylori was associated with the release of HDAC-1 from the p21 (WAF1) promoter and the hyperacetylation of histone 4 (87).

\section{Clinical implications of epigenetics}

The knowledge of epigenetic alterations could be potentially useful for cancer diagnosis and treatment. Aberrant promoter methylation occurs very early during carcinogenesis. $\mathrm{CpG}$ island hypermethylation may become one of the most promising biomarkers for the early detection of tumors. It may prove to be more beneficial than genetic studies, as promoter methylation occurs more frequently in tumors than genetic alterations in general and also due to the fact that several methylated loci may be analyzed simultaneously. Since promoter methylation occurs within a well defined region of a gene, epigenetic studies are more efficient and cost-effective. The overall survival rate for patients with gastric cancer is poor (10-20\%) (14). The early detection of lesions and/or reliable biomarkers for monitoring locoregional recurrence may increase the survival of patients with gastric cancer.

Epigenetic alterations in tumors may also be utilized in predicting tumor behaviour or prognosis of gastric cancer. The promoter hypermethylation of E-cadherin is associated with a poor prognosis (43). CDH1 promoter hypermethylation is more frequent in the diffuse histological type and is significantly higher with LN metastasis and serosal invasion $(44,88)$. DAPK correlates with the presence of LN metastasis, an advanced stage and poor survival (49). The methylation of SOCS-1 leads to a with reduced expression of the SOCS gene, LN metastases and an advanced tumor stage (60). The demethylation of both the MAGE-A1 and A3 promoters is observed in advanced clinical stages and is associated with a poor prognosis (75). SNCG demethylation is common in cases with LN metastasis. The trimethylation of $\mathrm{H} 3 \mathrm{~K} 9$ in gastric cancer is associated with an advanced tumor stage and lymphovascular invasion and the acetylation of histone $\mathrm{H} 3$ at $\mathrm{K} 9$ is present in the poorly differentiated or diffuse type of histology (79). The reduction of histone $\mathrm{H} 4$ acetylation correlates with a more advanced stage, deeper invasion and a greater extent of LN metastasis (85).

The recent development in the understanding of relevant gene silencing by epigenetic mechanisms in cancer development is closely linked to epigenetic drug design and development. These compounds function in three processes: DNA cytosine methylation, histone modification and nucleosomal remodeling. 
The two main classes of drugs are DNA methylation inhibitors and HDAC inhibitors (13). The various drugs which are widely used in clinical practice for the treatment of other conditions, such as hydralazine (hypertension), procainamide (cardiac arrhythmia), valproic acid (epilepsy) may now be used for the treatment of cancer (89-91).

The use of DNA methylation inhibitors is an attractive approach for the treatment of cancer, as the toxicity of these drugs to normal cells is potentially lower than that of conventional anticancer chemotherapeutic agents (16). DNA methylation inhibitors are divided into nucleoside and nonnucleoside analogues. The former are compounds that form a covalent intermediate complex with DNMT, preventing the cell from being methylated correctly. DNMT inhibitors, such as 5-azacytidine (Vidaza), 5-aza-deoxycytidine (decitabine) are the only two cytidine analogues that have been approved by the US Food and Drug Administration (FDA) for haematological malignancies $(92,93)$. Non-nucleoside analogues have an advantage over the analogues since they bind to the catalytic site of the enzyme DNMT and are not integrated into the DNA. Thus, this avoids the non-specific effects of nucleoside analogues (13). Hydralazine, a potent peripheral vasodilator, is currently also used as demethylating agent in cervical cancer (94).

HDAC inhibitors are divided into four groups: short chain fatty acids, hyroxamic acids, cyclic tetrapeptides and benzamides (13). The hydroxamic acid, trichostatin A (TSA), has been shown to be a chemosensitizer which increases the efficacy of chemotherapeutic drugs in gastric cancer (95). TSA is a promising chemotherapeutic agent in combination with 5-fluorouracil, paclitaxel and irinotecan in gastric cancer cells (95). Previously, (in October 2006) the FDA approved the first HDAC inhibitor, vorinostat 1 (SAHA) for the treatment of cutaneous T cell lymphoma (96). Various other HDAC inhibitors are currently undergoing clinical trials $(97,98)$.

Another novel method for the use of epigenetics in the treatment of cancer is the reactivation of key enzymes controlling the cellular response to anticancer drugs. Satoh et al (99) demonstrated that microtubule inhibitors, such as docetaxel and paclitaxel induce apoptosis in gastric cells with checkpoint with forkhead-associated and ring finger (CHFR) methylation. They found that gastric cancer cells not expressing CHFR lack a mitotic checkpoint and are highly susceptible to microtubule inhibitors. Thus, CHFR methylation may be a useful molecular marker to predict the responsiveness of gastric cancer to treatment with microtubule inhibitors. Koga et al (100) also reported CHFR methylation in predicting the response of microtubule inhibitors in the treatment of gastric cancer.

Epigenetics may be used in the future as a tool for the discovery of potential screening markers for the early detection of gastric cancer. Epigenetics studies may also be used as a risk assessment tool for the identification of individuals at risk of developing cancer. Epigenetics may be also used in clinical practice to predict tumor behaviour and for the prognosis of patients with gastric cancer, as well as for the identification of biomarkers to monitor the response to therapeutic agents. The other application of epigenetics is in therapy. DNA methylation inhibitors and HDAC inhibitors may be used as monotherapy or in combination with other anticancer drugs for the treatment of gastric cancer.

\section{References}

1. Ushijima T and Sasako M: Focus on gastric cancer. Cancer Cell 5: 121-125, 2004.

2. Smith MG, Hold GL, Tahara E and El-Omar EM: Cellular and molecular aspects of gastric cancer. World J Gastroenterol 12: 2979-2990, 2006.

3. Tahara E: Genetic pathways of two types of gastric cancer. IARC Sci Publ 157: 327-349, 2004.

4. Lee JH, Abraham SC, Kim HS, Nam JH, Choi C, Lee MC, Park CS, Juhng SW, Rashid A, Hamilton SR, et al: Inverse relationship between APC gene mutation in gastric adenomas and development of adenocarcinoma. Am J Pathol 161: 611-618, 2002.

5. Park WS, Oh RR, Park JY, Lee SH, Shin MS, Kim YS, Kim SY, Lee HK, Kim PJ, Oh ST, et al: Frequent somatic mutations of the beta-catenin gene in intestinal-type gastric cancer. Cancer Res 59: 4257-4260, 1999.

6. Maesawa C, Tamura G, Suzuki Y, Ogasawara S, Sakata K, Kashiwaba $M$ and Satodate R: The sequential accumulation of genetic alterations characteristic of the colorectal adenomacarcinoma sequence does not occur between gastric adenoma and adenocarcinoma. J Pathol 176: 249-258, 1995.

7. Becker KF, Atkinson MJ, Reich U, Becker I, Nekarda H, Siewert JR and Höfler H: E-cadherin gene mutations provide clues to diffuse type gastric carcinomas. Cancer Res 54: 3845-3852, 1994.

8. Li QL, Ito K, Sakakura C, Fukamachi H, Inoue K, Chi XZ, Lee KY, Nomura S, Lee CW, Han SB, et al: Causal relationship between the loss of RUNX3 expression and gastric cancer. Cell 109: 113-124, 2002.

9. Hirst $\mathrm{M}$ and Marra MA: Epigenetics and human disease. Int J Biochem Cell Biol 41: 136-146, 2009.

10. Panani AD: Cytogenetic and molecular aspects of gastric cancer: Clinical implications. Cancer Lett 266: 99-115, 2008.

11. Waddington CH: An Introduction to Modern Genetics. Allen \& Unwin, London, 1939.

12. Riggs AD, Martienssen RA and Ruso VEA: Epigenetic mechanisms of gene regulation. Cold Spring Harbor Laboratory Press 0-87969-490-4, 1996.

13. Mulero-Navarro S and Esteller M: Epigenetic biomarkers for human cancer: The time is now. Crit Rev Oncol Hematol 68: 1-11, 2008.

14. Khan FA and Shukla AN: Pathogenesis and treatment of gastric carcinoma: 'an up-date with brief review'. J Cancer Res Ther 2: 196-199, 2006.

15. Nitti D, Mocellin S, Marchet A, Pilati P and Lise M: Recent advances in conventional and molecular prognostic factors for gastric carcinoma. Surg Oncol Clin N Am 17: 467-483, 2008

16. Fan CY: Epigenetic alterations in head and neck cancer: Prevalence, clinical significance, and implications. Curr Oncol Rep 6: 152-161, 2004.

17. Tischoff I, Wittekind $\mathrm{C}$ and Tannapfel A: Role of epigenetic alterations in cholangiocarcinoma. J Hepatobiliary Pancreat Surg 13: 274-279, 2006.

18. Robertson KD: DNA methylation and human disease. Nat Rev Genet 6: 597-610, 2005.

19. Bird AP: CpG-rich islands and the function of DNA methylation. Nature 321: 209-213, 1986.

20. Nakajima T, Enomoto S and Ushijima T: DNA methylation: A marker for carcinogen exposure and cancer risk. Environ Health Prev Med 13: 8-15, 2008.

21. Calin GA and Croce CM: MicroRNA signatures in human cancers. Nat Rev Cancer 6: 857-866, 2006.

22. Chen CZ: MicroRNAs as oncogenes and tumor suppressors. N Engl J Med 353: 1768-1771, 2005.

23. Hinshelwood RA and Clark SJ: Breast cancer epigenetics: Normal human mammary epithelial cells as a model system. J Mol Med Berl 86: 1315-1328, 2008.

24. Jones PA and Baylin SB: The fundamental role of epigenetic events in cancer. Nat Rev Genet 3: 415-428, 2002.

25. Karpf AR and Jones DA: Reactivating the expression of methylation silenced genes in human cancer. Oncogene 21: 5496-5503, 2002.

26. Sparmann A and van Lohuizen M: Polycomb silencers control cell fate, development and cancer. Nat Rev Cancer 6: 846-856, 2006.

27. Lund AH and van Lohuizen M: Polycomb complexes and silencing mechanisms. Curr Opin Cell Biol 16: 239-246, 2004.

28. Thacker J: The RAD51 gene family, genetic instability and cancer. Cancer Lett 219: 125-135, 2005. 
29. Kim K, Park U, Wang J, Lee J, Park S, Kim S, Choi D, Kim C and Park J: Gene profiling of colonic serrated adenomas by using oligonucleotide microarray. Int J Colorectal Dis 23: 569-580, 2008

30. Mancino M, Strizzi L, Wechselberger C, Watanabe K, Gonzales M, Hamada S, Normanno N, Salomon DS and Bianco C: Regulation of human Cripto-1 gene expression by TGF-betal and BMP-4 in embryonal and colon cancer cells. J Cell Physiol 215-203, 2008.

31. Forn M, Díez-Villanueva A, Merlos-Suárez A, Muñoz M, Lois S, Carriò E, Jordà M, Bigas A, Batlle E and Peinado MA: Overlapping DNA methylation dynamics in mouse intestinal cell differentiation and early stages of malignant progression. PLoS One: 10: e0123263, 2015.

32. Bae JH, Kim JG, Heo K, Yang K, Kim TO and Yi JM: Identification of radiation-induced aberrant hypomethylation in colon cancer. BMC Genomics 16: 56, 2015

33. Ng JM and $\mathrm{Yu}$ J: Promoter hypermethylation of tumour suppressor genes as potential biomarkers in colorectal cancer. Int J Mol Sci 16: 2472-2496, 2015

34. An C, Choi IS, Yao JC, Worah S, Xie K, Mansfield PF, Ajani JA, Rashid A, Hamilton SR and Wu TT: Prognostic significance of $\mathrm{CpG}$ island methylator phenotype and microsatellite instability in gastric carcinoma. Clin Cancer Res 11: 656-663, 2005.

35. Song SH, Jong HS, Choi HH, Kang SH, Ryu MH, Kim NK, Kim WH and Bang YJ: Methylation of specific $\mathrm{CpG}$ sites in the promoter region could significantly down-regulate p16(INK4a) expression in gastric adenocarcinoma. Int J Cancer 87: 236-240, 2000.

36. Guimarães AC, Lima EM, Khayat AS, Girão Faria MH, Barem Rabenhorst SH, Pitombeira MV, Assumpção PP, de Oliveira Bahia M, Lima de Lima PD, de Arruda Cardoso Smith M, et al: Interrelationships among chromosome aneuploidy, promoter hypermethylation, and protein expression of the CDKN2A gene in individuals from northern Brazil with gastric adenocarcinoma. Cancer Genet Cytogenet 179: 45-51, 2007.

37. Lee JH, Park SJ, Abraham SC, Seo JS, Nam JH, Choi C, Juhng SW, Rashid A, Hamilton SR and Wu TT: Frequent CpG island methylation in precursor lesions and early gastric adenocarcinomas. Oncogene 23: 4646-4654, 2004

38. Fleisher AS, Esteller M, Wang S, Tamura G, Suzuki H, Yin J, Zou TT, Abraham JM, Kong D, Smolinski KN, et al: Hypermethylation of the hMLH1 gene promoter in human gastric cancers with microsatellite instability. Cancer Res 59: 1090-1095, 1999.

39. Leung SY, Yuen ST, Chung LP, Chu KM, Chan AS and Ho JC: hMLH1 promoter methylation and lack of hMLH1 expression in sporadic gastric carcinomas with high-frequency microsatellite instability. Cancer Res 59: 159-164, 1999.

40. Jung HY, Jung KC, Shim YH, Ro JY and Kang GH: Methylation of the hMLH1 promoter in multiple gastric carcinomas with microsatellite instability. Pathol Int 51: 445-451, 2001.

41. Zhang YJ, Chen Y, Ahsan H, Lunn RM, Lee PH, Chen CJ and Santella RM: Inactivation of the DNA repair gene O6-methylguanine-DNA methyltransferase by promoter hypermethylation and its relationship to aflatoxin B1-DNA adducts and p53 mutation in hepatocellular carcinoma. Int J Cancer 103: 440-444, 2003.

42. Zazula M, Ferreira AM, Czopek JP, Kolodziejczyk P, Sinczak-Kuta A, Klimkowska A, Wojcik P, Okon K, Bialas M, Kulig J, et al: $\mathrm{CDH} 1$ gene promoter hypermethylation in gastric cancer: Relationship to Goseki grading, microsatellite instability status, and EBV invasion. Diagn Mol Pathol 15: 24-29, 2006.

43. Graziano F, Arduini F, Ruzzo A, Bearzi I, Humar B, More H, Silva R, Muretto P, Guilford P, Testa E, et al: Prognostic analysis of E-cadherin gene promoter hypermethylation in patients with surgically resected, node-positive, diffuse gastric cancer. Clin Cancer Res 10: 2784-2789, 2004.

44. Liu WT, Jiao HL, Yang YL, Wang D and Zhang WM: Correlation of E-cadherin hypermethylation to tumorigenesis and development of gastric cancer. Ai Zheng 26: 1199-1203, 2007 (In Chinese).

45. Chan AO: E-cadherin in gastric cancer. World J Gastroenterol 12 199-203, 2006

46. Chan AO, Lam SK, Wong BC, Wong WM, Yuen MF, Yeung YH, Hui WM, Rashid A and Kwong YL: Promoter methylation of E-cadherin gene in gastric mucosa associated with Helicobacter pylori infection and in gastric cancer. Gut 52: 502-506, 2003.

47. Terrés AM, Pajares JM, O'Toole D, Ahern S and Kelleher D: $H$. pylori infection is associated with downregulation of E-cadherin, a molecule involved in epithelial cell adhesion and proliferation control. J Clin Pathol 51: 410-412, 1998.
48. Miotto E, Sabbioni S, Veronese A, Calin GA, Gullini S, Liboni A, Gramantieri L, Bolondi L, Ferrazzi E, Gafà R, et al: Frequent aberrant methylation of the $\mathrm{CDH} 4$ gene promoter in human colorectal and gastric cancer. Cancer Res 64: 8156-8159, 2004.

49. Chan AW, Chan MW, Lee TL, Ng EK, Leung WK, Lau JY, Tong JH, Chan FK and To KF: Promoter hypermethylation of Death-associated protein-kinase gene associated with advance stage gastric cancer. Oncol Rep 13: 937-941, 2005.

50. Byun DS, Lee MG, Chae KS, Ryu BG and Chi SG: Frequent epigenetic inactivation of RASSF1A by aberrant promoter hypermethylation in human gastric adenocarcinoma. Cancer Res 61: 7034-7038, 2001

51. Byun DS, Cho K, Ryu BK, Lee MG, Kang MJ, Kim HR and Chi SG: Hypermethylation of XIAP-associated factor 1, a putative tumor suppressor gene from the $17 \mathrm{p} 13.2$ locus, in human gastric adenocarcinomas. Cancer Res 63: 7068-7075, 2003.

52. Jee CD, Lee HS, Bae SI, Yang HK, Lee YM, Rho MS and Kim WH: Loss of caspase-1 gene expression in human gastric carcinomas and cell lines. Int J Oncol 26: 1265-1271, 2005.

53. Jung Y, Park J, Bang YJ and Kim TY: Gene silencing of TSPYL5 mediated by aberrant promoter methylation in gastric cancers. Lab Invest 88: 153-160, 2008.

54. Lee JH, Byun DS, Lee MG, Ryu BK, Kang MJ, Chae KS, Lee KY, Kim HJ, Park $\mathrm{H}$ and Chi SG: Frequent epigenetic inactivation of hSRBC in gastric cancer and its implication in attenuated p53 response to stresses. Int J Cancer 122: 1573-1584, 2008.

55. Sato H, Suzuki H, Toyota M, Nojima M, Maruyama R, Sasaki S, Takagi H, Sogabe Y, Sasaki Y, Idogawa M, et al: Frequent epigenetic inactivation of DICKKOPF family genes in human gastrointestinal tumors. Carcinogenesis 28: 2459-2466, 2007.

56. Cheng YY, Yu J, Wong YP, Man EP, To KF, Jin VX, Li J, Tao Q, Sung JJ, Chan FK, et al: Frequent epigenetic inactivation of secreted frizzled-related protein 2 (SFRP2) by promoter methylation in human gastric cancer. Br J Cancer 97: 895-901, 2007.

57. Nojima M, Suzuki H, Toyota M, Watanabe Y, Maruyama R Sasaki S, Sasaki Y, Mita H, Nishikawa N, Yamaguchi K, et al: Frequent epigenetic inactivation of SFRP genes and constitutive activation of Wnt signaling in gastric cancer. Oncogene 26: 4699-4713, 2007

58. Ebert MP, Yu J, Hoffmann J, Rocco A, Röcken C, Kahmann S, Müller O, Korc M, Sung JJ and Malfertheiner P: Loss of betacatenin expression in metastatic gastric cancer. J Clin Oncol 21: $1708-1714,2003$

59. Takada H, Imoto I, Tsuda H, Nakanishi Y, Sakakura C, Mitsufuji S, Hirohashi S and Inazawa J: Genomic loss and epigenetic silencing of very-low-density lipoprotein receptor involved in gastric carcinogenesis. Oncogene 25: 6554-6562, 2006.

60. Oshimo Y, Kuraoka K, Nakayama H, Kitadai Y, Yoshida K, Chayama K and Yasui W: Epigenetic inactivation of SOCS-1 by $\mathrm{CpG}$ island hypermethylation in human gastric carcinoma. Int J Cancer 112: 1003-1009, 2004

61. Choi MC, Jong HS, Kim TY, Song SH, Lee DS, Lee JW, Kim TY, Kim NK and Bang YJ: AKAP12/Gravin is inactivated by epigenetic mechanism in human gastric carcinoma and shows growth suppressor activity. Oncogene 23: 7095-7103, 2004.

62. Oshimo Y, Oue N, Mitani Y, Nakayama H, Kitadai Y, Yoshida K, Chayama K and Yasui W: Frequent epigenetic inactivation of RIZ1 by promoter hypermethylation in human gastric carcinoma. Int J Cancer 110: 212-218, 2004.

63. Yamamichi N, Inada K, Ichinose M, Yamamichi-Nishina M, Mizutani T, Watanabe H, Shiogama K, Fujishiro M, Okazaki T, Yahagi N, et al: Frequent loss of Brm expression in gastric cancer correlates with histologic features and differentiation state. Cancer Res 67: 10727-10735, 2007.

64. Hamai Y, Oue N, Mitani Y, Nakayama H, Ito R, Matsusaki K, Yoshida K, Toge T and Yasui W: DNA hypermethylation and histone hypoacetylation of the HLTF gene are associated with reduced expression in gastric carcinoma. Cancer Sci 94: 692-698, 2003.

65. Kim TY, Lee HJ, Hwang KS, Lee M, Kim JW, Bang YJ and Kang GH: Methylation of RUNX3 in various types of human cancers and premalignant stages of gastric carcinoma. Lab Invest 84: 479-484, 2004.

66. Hayashi K, Yokozaki H, Goodison S, Oue N, Suzuki T, Lotan R, Yasui $\mathrm{W}$ and Tahara E: Inactivation of retinoic acid receptor beta by promoter $\mathrm{CpG}$ hypermethylation in gastric cancer. Differentiation 68: 13-21, 2001.

67. Oue N, Matsumura S, Nakayama H, Kitadai Y, Taniyama K, Matsusaki K and Yasui W: Reduced expression of the TSP1 gene and its association with promoter hypermethylation in gastric carcinoma. Oncology 64: 423-429, 2003. 
68. Kim TY, Jong HS, Song SH, Dimtchev A, Jeong SJ, Lee JW, Kim TY, Kim NK, Jung M and Bang YJ: Transcriptional silencing of the DLC-1 tumor suppressor gene by epigenetic mechanism in gastric cancer cells. Oncogene 22: 3943-3951, 2003.

69. Yu J, Leung WK, Lee TL, Tse PC, To KF and Sung JJ: Promoter hypermethylation of cyclooxygenase-2 in gastric carcinoma. Int J Oncol 22: 1025-1031, 2003

70. de Maat MF, van de Velde CJ, Umetani N, de Heer P, Putter H, van Hoesel AQ, Meijer GA, van Grieken NC, Kuppen PJ, Bilchik AJ, et al: Epigenetic silencing of cyclooxygenase-2 affects clinical outcome in gastric cancer. J Clin Oncol 25: 4887-4894, 2007.

71. Poplawski T, Tomaszewska K, Galicki M, Morawiec Z and Blasiak J: Promoter methylation of cancer-related genes in gastric carcinoma. Exp Oncol 30: 112-116, 2008.

72. Lee TL, Leung WK, Chan MW, Ng EK, Tong JH, Lo KW, Chung SC, Sung JJ and To KF: Detection of gene promoter hypermethylation in the tumor and serum of patients with gastric carcinoma. Clin Cancer Res 8: 1761-1766, 2002.

73. Kang GH, Lee S, Kim JS and Jung HY: Profile of aberrant CpG island methylation along multistep gastric carcinogenesis. Lab Invest 83: 519-526, 2003.

74. Oue N, Motoshita J, Yokozaki H, Hayashi K, Tahara E, Taniyama K, Matsusaki K and Yasui W: Distinct promoter hypermethylation of p16 $6^{\mathrm{INK} 4 \mathrm{a}}, \mathrm{CDH} 1$, and RAR-beta in intestinal, diffuse-adherent, and diffuse-scattered type gastric carcinomas. J Pathol 198: 55-59, 2002

75. Honda T, Tamura G, Waki T, Kawata S, Terashima M, Nishizuka S and Motoyama T: Demethylation of MAGE promoters during gastric cancer progression. Br J Cancer 90: 838-843, 2004.

76. Yanagawa N, Tamura G, Honda T, Endoh M, Nishizuka S and Motoyama T: Demethylation of the synuclein gamma gene $\mathrm{CpG}$ island in primary gastric cancers and gastric cancer cell lines. Clin Cancer Res 10: 2447-2451, 2004.

77. Lima EM, Leal MF, Burbano RR, Khayat AS, Assumpção PP, Bello MJ, Rey JA, Smith MA and Casartelli C: Methylation status of ANAPC1, CDKN2A and TP53 promoter genes in individuals with gastric cancer. Braz J Med Biol Res 41: 539-543, 2008.

78. Park YS, Jin MY, Kim YJ, Yook JH, Kim BS and Jang SJ: The global histone modification pattern correlates with cancer recurrence and overall survival in gastric adenocarcinoma. Ann Surg Oncol 15: 1968-1976, 2008.

79. Heard E, Rougeulle C, Arnaud D, Avner P, Allis CD and Spector DL: Methylation of histone H3 at Lys-9 is an early mark on the $\mathrm{X}$ chromosome during $\mathrm{X}$ inactivation. Cell 107: 727-738, 2001.

80. Mermoud JE, Popova B, Peters AH, Jenuwein T and Brockdorff N: Histone $\mathrm{H} 3$ lysine 9 methylation occurs rapidly at the onset of random X chromosome inactivation. Curr Biol 12: 247-251, 2002.

81. Nguyen CT, Weisenberger DJ, Velicescu M, Gonzales FA, Lin JC, Liang G and Jones PA: Histone H3-lysine 9 methylation is associated with aberrant gene silencing in cancer cells and is rapidly reversed by 5-aza-2'-deoxycytidine. Cancer Res 62 : 6456-6461, 2002.

82. Schotta G, Lachner M, Sarma K, Ebert A, Sengupta R, Reuter G, Reinberg D and Jenuwein T: A silencing pathway to induce $\mathrm{H} 3-\mathrm{K} 9$ and $\mathrm{H} 4-\mathrm{K} 20$ trimethylation at constitutive heterochromatin. Genes Dev 18: 1251-1262, 2004.

83. Kondo Y, Shen L and Issa JP: Critical role of histone methylation in tumor suppressor gene silencing in colorectal cancer. Mol Cell Biol 23: 206-215, 2003.

84. Watanabe Y, Toyota M, Kondo Y, Suzuki H,Imai T, Ohe-Toyota M, Maruyama R, Nojima M, Sasaki Y, Sekido Y, et al: PRDM5 identified as a target of epigenetic silencing in colorectal and gastric cancer. Clin Cancer Res 13: 4786-4794, 2007.
85. Ono S, Oue N, Kuniyasu H, Suzuki T, Ito R, Matsusaki K, Ishikawa T, Tahara E and Yasui W: Acetylated histone H4 is reduced in human gastric adenomas and carcinomas. J Exp Clin Cancer Res 21: 377-382, 2002

86. Mitani Y, Oue N, Hamai Y, Aung PP, Matsumura S, Nakayama H, Kamata $\mathrm{N}$ and Yasui W: Histone $\mathrm{H} 3$ acetylation is associated with reduced $\mathrm{p} 21$ (WAF1/CIP1) expression by gastric carcinoma. J Pathol 205: 65-73, 2005.

87. Xia G, Schneider-Stock R, Diestel A, Habold C, Krueger S, Roessner A, Naumann M and Lendeckel U: Helicobacter pylori regulates $\mathrm{p} 21$ (WAF1) by histone $\mathrm{H} 4$ acetylation. Biochem Biophys Res Commun 369: 526-531, 2008.

88. Yi Kim D, Kyoon Joo J, Kyu Park Y, Yeob Ryu S, Soo Kim H, Kyun Noh B, Hwa Lee K and Hyuk Lee J: E-cadherin expression in early gastric carcinoma and correlation with lymph node metastasis. J Surg Oncol 96: 429-435, 2007.

89. Rich S, Ganz R and Levy PS: Comparative actions of hydralazine, nifedipine and amrinone in primary pulmonary hypertension. Am J Cardiol 52: 1104-1107, 1983.

90. Windle J, Prystowsky EN, Miles WM and Heger JJ: Pharmacokinetic and electrophysiologic interactions of amiodarone and procainamide. Clin Pharmacol Ther 41: 603-610, 1987.

91. Strolin Benedetti M, Rumigny JF and Dostert P: Mechanisms of action and biochemical toxicology of valproic acid. Encephale 10: 177-188, 1984 (In French).

92. Kaminskas E, Farrell A, Abraham S, Baird A, Hsieh LS, Lee SL, Leighton JK, Patel H, Rahman A, Sridhara R, et al; FDA: Approval summary: Azacitidine for treatment of myelodysplastic syndrome subtypes. Clin Cancer Res 11: 3604-3608, 2005.

93. Issa JP, Gharibyan V, Cortes J, Jelinek J, Morris G, Verstovsek S, Talpaz M, Garcia-Manero G and Kantarjian HM: Phase II study of low-dose decitabine in patients with chronic myelogenous leukemia resistant to imatinib mesylate. J Clin Oncol 23: 3948-3956, 2005.

94.Zambrano P, Segura-Pacheco B, Perez-Cardenas E, Cetina L, Revilla-Vazquez A, Taja-Chayeb L, Chavez-Blanco A, Angeles E, Cabrera G, Sandoval K, et al: A phase I study of hydralazine to demethylate and reactivate the expression of tumor suppressor genes. BMC Cancer 5: 44, 2005.

95. Zhang X, Yashiro M, Ren J and Hirakawa K: Histone deacetylase inhibitor, trichostatin A, increases the chemosensitivity of anticancer drugs in gastric cancer cell lines. Oncol Rep 16: 563-568, 2006.

96. Riester D, Hildmann C and Schwienhorst A: Histone deacetylase inhibitors - turning epigenic mechanisms of gene regulation into tools of therapeutic intervention in malignant and other diseases. Appl Microbiol Biotechnol 75: 499-514, 2007

97. Ji M, Lee EJ, Kim KB, Kim Y, Sung R, Lee SJ, Kim DS and Park SM: HDAC inhibitors induce epithelial-mesenchymal transition in colon carcinoma cells. Oncol Rep 33: 2299-2308, 2015.

98. Kang Y, Nian H, Rajendran P, Kim E, Dashwood WM, Pinto JT, Boardman LA, Thibodeau SN, Limburg PJ, Löhr CV, et al: HDAC8 and STAT3 repress BMF gene activity in colon cancer cells. Cell Death Dis 5: e1476, 2014.

99. Satoh A, Toyota M, Itoh F, Sasaki Y, Suzuki H, Ogi K, Kikuchi T, Mita H, Yamashita T, Kojima T, et al: Epigenetic inactivation of CHFR and sensitivity to microtubule inhibitors in gastric cancer. Cancer Res 63: 8606-8613, 2003.

100. Koga Y, Kitajima Y, Miyoshi A, Sato K, Sato S and Miyazaki K: The significance of aberrant CHFR methylation for clinical response to microtubule inhibitors in gastric cancer. J Gastroenterol 41: 133-139, 2006. 